\title{
ECOTOXICOLOGICAL EVALUATION THROUGH ALLIUM CEPA OF FOOD INDUSTRY EFFLUENT TREATED BY PROCESS USING MEMBRANES
}

\author{
KERBER, Luana ${ }^{1}$; MARIOTTI, Paula ${ }^{1}$; VOGNACH, Letícia ${ }^{1}$; TASSINARY, João Alberto ${ }^{1}$; \\ STÜLP, Simone ${ }^{*}$
}

${ }^{1}$ Universidade do Vale do Taquari - UNIVATES, Núcleo de Eletrofotoquímica e Materiais Poliméricos.

Av. Avelino Talini, 171, CEP 95914-014, Lajeado - RS, Brasil

(Fone: +555137147000 ramal 5908)

* Simone Stülp

e-mail: stulp@univates.br

\section{RESUMO}

Com o aumento populacional há uma tendência de incremento dos processos de degradação dos recursos hídricos. Sendo que um dos maiores poluidores é o lançamento de efluentes industriais e domésticos, sem o devido tratamento, nos cursos d'água. $O$ reuso e reutilização de efluentes tem como alternativa minimizar o lançamento de resíduos, evitando assim uma sobrecarga no sistema de tratamento e muitas vezes auxiliando na redução de custos. O objetivo deste trabalho é avaliar a aplicação da técnica de osmose reversa sobre efluente de indústria alimentícia, em termos físico-químicos e toxicológicos. Foi realizada a aplicação da técnica de osmose reversa, e o efluente antes e após o tratamento foi avaliado em termos de $\mathrm{pH}$, Turbidez, Coloração, Condutividade, Oxigênio dissolvido, Carbono Orgânico Total e Nitrogênio Total, além de avaliações toxicológicas (Allium cepa). Com base nos resultados obtidos verifica-se que a técnica de osmose reversa apresentou eficiência de tratamento quando aplicada ao efluente contendo corantes e isoflavona de soja, em termos de avaliações físicas e químicas. Em termos de avaliação toxicológica, em relação ao desenvolvimento radicular, o efluente tratado (permeado) apresentou um crescimento das radículas, sendo que o efluente bruto não desenvolveu radícula alguma.

Palavras-chave:Efluente; Osmose reversa; Ecotoxicologia.

\section{ABSTRACT}

Due to population growth, there is an increase in the tendency of water resource degradation. One of the biggest polluters is the practice of dumping industrial and domestic effluents without any treatment on the watercourse. The utilization of effluents is an alternative to minimize the inadequate waste dump, thus avoiding the overload on the treatment system as well as cutting down costs and expenses. This work's objective is to evaluate the application of reverse osmosis in a food industrial effluent, in physicochemical and toxicological terms. A reverse osmosis technical application was conducted and then the effluent was examined, before and afterward, in terms of $\mathrm{pH}$, Turbidity, Colouring, Conductivity, Dissolved Oxygen, Total Organic Carbon, and Total Nitrogen as well as a toxicological evaluation (Allium cepa). According to the obtained result, it can be identified that the technique of reverse osmosis showed treatment efficiency when applied to the effluent containing coloring and soy isoflavones, with regards to the physicals and chemical evaluation. In terms of toxicological evaluation, with respect to the radicular development, the treated effluent (permeate) showed a radicular growth, once the raw effluent did not develop any root.

Keywords: Effluent, Reverse Osmosis, Ecotoxicology 


\section{INTRODUÇÃO}

Uma das maiores causas da poluição do ambiente aquático é o lançamento de efluentes industriais e domésticos, sem 0 devido tratamento, diretamente nos cursos de água (Metcalf \& Eddy, 2004). Quando não há o adequado tratamento dos efluentes antes do descarte, há a consequente contribuição para degradação dos recursos hídricos. Dessa maneira, é vital que estes recursos sejam avaliados e protegidos conciliando-os com as demandas de água para as atividades humanas (Bonumá, 2006).

Uma das indústrias que mais cresce mundialmente é a alimentícia, e dentre elas a de doces se destaca, além de processados contendo corantes, aumentando anualmente o seu faturamento (Prado; Godoy, 2007). Assim, a competitividade cresce, e as empresas precisam investir em produtos de qualidade e atraentes que se destaquem perante aos outros, de forma a garantir o seu sucesso de venda. Para isso, fazem uso de uma gama de aditivos alimentícios (Prado; Godoy, 2003 e 2007).

Ao final da produção de alimentos, são gerados efluentes que contêm resíduos dos aditivos e compostos adicionados durante o processamento. Este tipo de efluente é composto por corantes, flavonoides e isoflavonas, que antes do descarte necessitam de um tratamento, para não ocasionarem contaminação ao meio ambiente, principalmente em corpos hídricos (Prado; Godoy, 2003).

A legislação ambiental brasileira está cada vez mais condicionante e exigente quando se trata de emissão de efluentes tóxicos (CONSEMA №129/2006). Diversos efluentes são bastante complexos do ponto de vista físicoquímico, estes contribuem com ampla diversidade de poluentes para 0 ambiente aquático, logo, seus efeitos biológicos não podem ser evidenciados somente por análises tradicionais.

O tratamento necessário para a recuperação da água residual está intimamente relacionado com as especificações de aplicação do reuso associado à qualidade da água requerida. Os sistemas de tratamento envolvem a aplicação de processo de separação, tais como de misturas sólido líquido e também sua desinfecção. Em alguns casos podem ser aplicados tratamentos que envolvam uma combinação de processos físico, químico e biológico (Ferraro, 2008).

Em geral, a qualidade da água pode ser avaliada de duas formas distintas, embora complementares: uma é a análise química que identifica e quantifica as substâncias; a outra é a análise biológica que qualifica os efeitos causados pelas substâncias como, por exemplo, as análises microbiológicas, hidrobiológicas e ecotoxicológicas.

No entanto, levando-se em consideração a enorme quantidade de compostos químicos que podem chegar às águas, a análise química tornase muito limitada e, em geral, não permite uma avaliação dos efeitos das substâncias sobre os seres vivos. Essa lacuna é preenchida pelos métodos biológicos de avaliação (Kapanen e Itävaara, 2001).

Os testes de toxicidade apresentam algumas vantagens (Farre' e Barcelo, 2003): medem a toxicidade mesmo quando o agente tóxico é desconhecido, têm caráter preditivo (fornecendo advertência de potenciais danos ambientais antes que o ecossistema seja severamente comprometido), são usualmente menos custosos que as análises químicas, apresentam respostas em curto período de tempo, as espécies utilizadas são de fácil manutenção.

O reuso e reutilização de efluentes tem como alternativa minimizar os resíduos descartados, evitando assim uma sobrecarga no sistema de tratamento e muitas vezes auxiliando na redução de custos. Diferentes alternativas podem ser aplicadas para que o reuso possa ser viabilizado, dado que diferentes características de atividades e posteriores aplicações podem ser requeridas (Anjaneyulu et al., 2005).

Entre os diversos tipos de tratamento de efluentes e tecnologias que visam o reuso, a osmose reversa é uma opção, onde a operação do sistema consiste no solvente que é separado da solução, mediante sua passagem por uma membrana semipermeável não porosa, desenvolvida para reter sais e solutos com baixos pesos moleculares (Pérez-González et al., 2012).

Neste sentido, este estudo visou avaliar os efeitos do processo de osmose reversa com avaliações toxicológicas utilizando Allium cepa, sobre efluente oriundo de indústria do ramo alimentício em termos de impacto físico-químico e ecotoxicológico, a fim de melhorar a qualidade 
da água lançada no meio ambiente e minimizar a contaminação e possíveis efeitos prejudiciais ao ambiente.

\section{MATERIAL E MÉTODOS}

O efluente sintético utilizado neste estudo é composto de uma solução aquosa contendo 1 $\mathrm{g} / \mathrm{L}$ de sacarose grau alimentício $\left(0,33 \mathrm{~g} \mathrm{~L}^{-1}\right)$, $1 \mathrm{~g} / \mathrm{L}$ de corante carmim de cochonilha $\left(30 \mathrm{mg} \mathrm{L}^{-}\right.$ ${ }^{1}$ ), da marca Duas Rodas e 16,2 g de proteína isolada de soja (contendo isoflavona), da marca Verde Flora. Foi utilizado como base para o efluente sintético, a composição do resíduo após obtenção industrial de suco de soja aromatizado.

Para o tratamento do efluente usando a técnica de osmose reversa, foi utilizado um tanque de alimentação com sistema de filtração, acoplado à uma unidade de osmose reversa. $O$ tanque foi alimentado com o efluente, que sofreu pressão mecânica promovendo um fluxo do efluente sobre a membrana orgânica. Ao passar pela membrana, a solução é separada em duas partes distintas: o permeado, que é a parte da solução que atravessou a membrana, ficando com alto grau de pureza; e o rejeito, que percorreu a membrana, mas não a atravessou. Nos ensaios realizados foi utilizada membrana orgânica de acetato de celulose, polissulfona, polietersulfona, poliamida ( $\mathrm{pH}$ 3-10), com tamanho do poro de 1 a 10 Angstrom. A pressão utilizada foi entre 25 e 30 bar, e o fluxo observado no sistema foi de $27,7 \mathrm{~L} / \mathrm{h}$.

Após o processo, as três soluções (efluente bruto, permeado e retentado) foram submetidos a análises físico-químicas e toxicológicas e comparadas aos parâmetros das resoluções vigentes, que foram: CONAMA № 357, de 17 de março de 2005; CONAMA № 430, de 13 de maio de 2011 e CONSEMA № 129, de 07 de dezembro de 2006, para posterior avaliação da sua qualidade.

As análises físico-químicas de $\mathrm{pH}$, Turbidez, Coloração, Condutividade, Oxigênio dissolvido (OD), Carbono Orgânico Total (COT) e Nitrogênio Total (NT), foram realizadas no Laboratórios de Química da Universidade do Vale do Taquari, UNIVATES.

Para a análise de $\mathrm{pH}$, de turbidez e condutividade foram coletados $100 \mathrm{~mL}$ do efluente bruto, $100 \mathrm{~mL}$ do permeado e $100 \mathrm{~mL}$ do retentado, ambos sem Beckers de vidro, para posterior medição. Para análise de pH utilizou-se o medidor de $\mathrm{pH}$ Digimed DM-20, para turbidez, - Turbidímetro Digimed DM TU e para condutividade, o condutivímetro da Metrohm, modelo 856 Conductivity Module. Ainda, foi determinada a coloração (colorímetro, modelo DM-50, da Digimed). Para análise de Carbono Orgânico Total (COT) foi utilizado o analisador de carbono Shimadzu, já para a análise de nitrogênio total foi utilizado medidor de nitrogênio TNM1 Shimadzu.

As avaliações de toxicidade, seguiram os procedimentos descritos por Fiskesjö (1985) e se enquadraram no protocolo de Barbério et al. (2011). Para cada tipo de efluente, foram selecionados três bulbos de Allium cepa de tamanho semelhante, com ausência de traumas, deformidades naturais ou contaminação por fungos. O anel radicular foi lavado em água corrente e água destilada antes do início do teste. Os bulbos foram transferidos para recipientes com $50 \mathrm{~mL}$ de cada amostra de efluente selecionado e mantidos à temperatura ambiente para germinação.

O efluente era trocado após 24 h, 48 h e 72 $h$, e os controles foram realizados em água destilada para o controle negativo e $25 \mathrm{mg} \mathrm{L}^{-1}$ de solução de sulfato de cobre para o controle positivo. As radículas foram medidas $(\mathrm{cm})$ após $72 \mathrm{~h}$ de germinação. As radículas retiradas foram submetidas a fixação em Carnoy (álcool - ácido acético, 3:1), por 24 horas à temperatura ambiente.

Ao final desta etapa, o material foi lavado em água destilada e inserido em etanol (70\%) por mais 12 horas sob refrigeração. Após esta última etapa, as radículas foram lavadas mais uma vez com água destilada, após foi retirado o excesso de água e então submetidas à hidrólise ácida em $\mathrm{HCl}(1 \mathrm{~N})$ por $5 \mathrm{~min}$. Após foram encaminhadas para o preparo das lâminas histológicas. Para esta etapa, foram selecionadas três radículas de cada amostra, no qual foi retirado a parte final para o preparo da lâmina. O fragmento foi colocado na lâmina, sobre orceína $2 \%$, esmagado com lamínula e submetido à microscopia de luz, a fim de se observar alguma deformidade nas paredes celulares dos meristemas selecionados.

\section{RESULTADOS E DISCUSSÃO}

\subsection{Análises físico-químicas}


O monitoramento da qualidade do efluente antes e após tratamento requer avaliações preliminares de suas características, e isso nos leva a realizar um estudo prévio do material a ser analisado. Parâmetros tais como Turbidez, pH, Coloração, Condutividade, Carbono Orgânico, Nitrogênio Total, Oxigênio Dissolvido (OD), Demanda Bioquímica de Oxigênio (DBO) dentre outros, são rotineiramente utilizados para 0 monitoramento da qualidade em amostras de efluentes, fornecendo dados importantes sobre o objeto de estudo (Oliveira et al., 2012).

Segundo resoluções $\mathrm{n}-357 / 2005$ e $\mathrm{n}-430 / 2011$ do Conselho Nacional do Meio Ambiente (CONAMA) e resolução no 128/2006 do Conselho Estadual do Meio Ambiente do Rio Grande do Sul (CONSEMA), os parâmetros desejados para os efluentes lançados em corpos d'água são os seguintes (Tabela 1):

Tabela 1 -Exemplos devalores de referência para os parâmetros físico-químicos analisados.

\begin{tabular}{c|c}
\hline $\begin{array}{c}\text { Parâmetros } \\
\text { analisados }\end{array}$ & $\begin{array}{c}\text { Valores de } \\
\text { referência }\end{array}$ \\
\hline $\mathrm{pH}$ & 5 a 9 \\
\hline Temperatura & Inferior a $40^{\circ} \mathrm{C}$ \\
\hline $\begin{array}{c}\text { Nitrogênio Total (NT) - } \\
\text { dependente da vazão de } \\
\text { descarte. }\end{array}$ & $20 \mathrm{mg} / \mathrm{L}$ \\
\hline
\end{tabular}

Fonte: Conama/Consema

De maneira geral, os parâmetros físicoquímicos do efluente bruto estudado apresentaram valores extremamente elevados em relação às resoluções em vigor, em termos de parâmetros para descarte. Após tratamento, o resíduo permeado permaneceu nos limites previstos nas resoluções ambientais vigentes. Já para o efluente retentado, os parâmetros indicam maiores concentrações em relação ao efluente bruto. Os resultados das análises físico-químicas das amostras de efluente são mostrados na Tabela 2.

Em relação ao parâmetro $\mathrm{pH}$ da água, os efluentes bruto e retentado atingiram valores próximos ( $\mathrm{pH}: 6,37$ e 6,65, respectivamente) ao mínimo exigido pela Resolução do Consema $(\mathrm{pH}$ : 6 a 9). Já o efluente permeado apresentou valor próximo à neutralidade $(\mathrm{pH}:$ 7,32), permanecendo em conformidade com os padrões de qualidade estabelecidos pelas resoluções em vigor. Resultados semelhantes foram encontrados por Filho \& Chui (2006) e Mendes et al. (2012).

Filho \& Chui (2006) relatam que condição de $\mathrm{pH}$ dos efluentes decorre da contaminação provocada pelos diversos processos industriais de fabricação, onde contato da água com substâncias como soda cáustica, potassa cáustica, cal, entre outras, libera um efluente final alcalino, por exemplo, altamente prejudicial aos mananciais, necessitando de uma solução corretiva para redução do $\mathrm{pH}$ para níveis toleráveis, daí a sua importância de estar dentro dos padrões permitidos. Logo os padrões de $\mathrm{pH}$ do efluente tratado-permeado estão dentro dos padrões.

Já em relação ao parâmetro turbidez, os efluentes bruto e retentados atingiram níveis elevados para este parâmetro, isso ocorre devido à grande quantidade de sólidos em suspensão oriundos dos corantes adicionados aos alimentos. Já o efluente permeado apresentou valor adequado para turbidez, demonstrando a eficiência do processo para o tratamento do efluente.

Quanto a coloração, os efluentes bruto e retentado novamente atingiram valores muito acima dos valores de referência. $\mathrm{O}$ efluente bruto apresentou níveis altos (46 PTCo) de coloração. Já o efluente permeado apresentou baixos níveis de coloração (6 PTCo), considerando que efluentes não devem conferir mudança de coloração (cor verdadeira) ao corpo hídrico receptor. A coloração da água prove grau de concentração de sólidos dissolvidos provenientes da dissolução de materiais orgânicos. Segundo Cornationi (2010), "a coloração da água é esteticamente indesejável para o consumidor em sistemas públicos de abastecimento de água e economicamente prejudicial para algumas indústrias".

Quanto à condutividade, os efluentes bruto e retentado apresentaram valores altos em função da quantidade de compostos presentes. Já o efluente permeado apresentou interessante diminuição em função da aplicação do tratamento. Quando há a presença de altos valores de condutividade (íons em solução), o ambiente pode estar impactado por ações antrópicas além de que valores elevados de CE podem indicar características corrosivas da água (CETESB, 2009). 
Para o nitrogênio total, os efluentes bruto e retentado atingiram valores de 2 vezes maiores que os valores de referência, que é de $20 \mathrm{mg} / \mathrm{L}$. $\mathrm{O}$ efluente permeado esteve dentro dos valores esperados, atingindo o valor de $4,80 \mathrm{mg} / \mathrm{L}$. O NT demonstra a contribuição total de nutrientes em água e quanto a liberação do efluente não tratado pode influenciar o nível de eutrofização da mesma. O nitrogênio é um elemento do metabolismo de ecossistemas aquáticos, sendo fator limitante na produção primária. A liberação do efluente não tratado diretamente ao corpo d'água pode gerar diversos problemas, devido à proliferação de algas. Ao mesmo tempo que essas algas produzem $\mathrm{O}_{2}$, elas o consomem, provocando a mortandade da biota associada e a proliferação de bactérias e outros microrganismos anaeróbicos, quase sempre associados a doenças (Palma-Silva, 1999). Os níveis do efluente permeado ficaram bem abaixo dos valores de referência, não havendo a possibilidade de causar problemas aos corpos d'água e a biota associada, sem pôr em risco à saúde humana.

Para o carbono orgânico total, os efluentes bruto e retentado atingiram valores de 699,7 $\mathrm{mg} / \mathrm{L}$ e $847,5 \mathrm{mg} / \mathrm{L}$, valores estes elevados para descarte. Já o efluente permeado apresentou valores inferiores, da ordem de $6,7 \mathrm{mg} / \mathrm{L}$. A quantidade de carbono orgânico presente no efluente, refere-se à quantidade de matéria orgânica disponível na solução. Observa-se a grande quantidade de matéria orgânica presente no efluente bruto, que ao ser descartado sem tratamento, servirá de alimento para os microorganismos de origem aeróbica, que consumirão todo oxigênio dissolvido (OD), na realização de seus processos respiratórios, causando uma redução deste no corpo d'água e prejudicando toda biota associada (Azzolini et al., 2011). Além do mais, a redução de OD na água pode causar a proliferação de microrganismos patogênicos, ocasionando problemas de âmbito sanitário. Para o Oxigênio Dissolvido (OD), os efluentes bruto e retentado atingiram os valores de $5,11 \mathrm{mg} / \mathrm{L}$ e $3,51 \mathrm{mg} / \mathrm{L}$, já o efluente tratado, $7,09 \mathrm{mg} / \mathrm{L}$. O índice de OD é um dos parâmetros mais importantes para avaliar a capacidade de um corpo hídrico em suportar a atividade biológica de organismos aquáticos. $O$ baixo nível de oxigênio dissolvido, conforme Janzen et al. (2008) indica consumo de oxigênio por decomposição da matéria orgânica ou respiração realizada por microrganismos.
As trocas gasosas com a atmosfera e a fotossínteses são os principais fornecedores de oxigênio para o corpo hídrico, sendo que temperaturas elevadas e diminuição da pressão atmosférica diminuem sua solubilidade (Wetzel, 2001). Além deste, outros fatores contribuem para a redução de oxigênio da água, tais como as perdas para a atmosfera, respiração de organismos aquáticos, processos de oxidação de íons metálicos e decomposição aeróbia (Esteves, 1988). Dessa forma, a concentração de oxigênio dissolvido em um corpo hídrico pode ser usada como uma das variáveis para a determinação da qualidade da água, pois quanto mais reduzida foi a concentração de oxigênio dissolvido, pode-se dizer que, mais poluído o curso d'água se encontra (Prado, 1999), influenciando diretamente na biodiversidade aquática.

\subsection{Parâmetros toxicológicos}

A espécie Allium cepa foi selecionada para - experimento desenvolvido neste trabalho devido à sua rapidez e alta taxa de germinação, comprovada em estudos preliminares (Alvin et al., 2011). Além disso, o comportamento cromossômico dessa espécie é conhecido, permitindo a obtenção de resultados consistentes.

Constatou-se que na maior parte das amostras, em quase todas as concentrações testadas, houve a promoção do crescimento radicular significativo, a não ser no efluente bruto, cujo não desenvolveu radícula alguma.

Quando comparado o número de radículas (em unidades), o efluente retentado apresentou média de 21 unidades, seguido pelo permeado e controle negativo, com 20 unidades, o controle positivo apresentou média de 7 unidades e o bruto, nenhuma. Segundo a análise de variância, o número de radículas variou significativamente entre os tratamentos ( $F 4,14: 4.218 ; \mathrm{p}=0.02954)$. $\mathrm{O}$ crescimento de radículas foi menor no efluente bruto do que no efluente permeado, retentado e controle negativo, conforme Figura 1.

Em relação ao desenvolvimento radicular, o efluente tratado permeado se destaca com um crescimento médio de $1,23 \mathrm{~cm}$, seguido pelo controle negativo, com média de $0,72 \mathrm{~cm}$, retentado com média de $0,44 \mathrm{~cm}$, controle positivo com $0,14 \mathrm{~cm}$ e o efluente bruto não desenvolveu radícula alguma. A análise de variância demonstrou que o crescimento variou significativamente entre os tratamentos (F4,14: 
8.335; $p=0.003)$. O crescimento de radículas foi maior no permeado do que no efluente retentado, bruto e controle positivo, conforme a Figura 2.

Alvim et al. (2011) relatam que qualquer mudança nas condições ambientais, principalmente por causa da poluição, pode ser observada nas plantas pela redução do crescimento radicular. Os resultados encontrados corroboram com os achados de Samuel et al. (2010) que verificaram um significativo efeito inibitório de um efluente têxtil para raízes de bulbos de Allium cepa, não havendo crescimento algum de raízes.

Em relação ao efluente retentado, o crescimento radicular neste efluente foi superior aos demais tratamentos. Uma explicação pertinente está relacionada à matéria orgânica e macronutrientes não removidos durante 0 tratamento, que podem estimular o alongamento radicular, diminuindo a sensibilidade do teste e/ou mascarando um possível efeito tóxico (Rodrigues; Bianchini, 2007). Nesse contexto, os nutrientes presentes nesses resíduos (por exemplo, Nitrogênio e Fósforo), bem como elevada carga de matéria orgânica presente no efluente retentado possui efeito promotor ao alongamento de raízes. Como ocorre com os nutrientes, parte da carga orgânica do efluente final pode vir do próprio efluente bruto, proveniente do processo industrial, e parte pode ser adicionada durante o tratamento biológico (Eremektar et al., 2007).

Quanto à análise histológica das radículas, em nenhuma das regiões meristemáticas analisadas foi visualizado alterações nas paredes celulares.

Knasmüller et al. (1998), considerou o uso de plantas na avaliação de toxicidade em ambientes aquáticos, e chegou à conclusão de que os dados atualmente disponíveis indicam que os bioensaios com vegetais podem ser parte integrante da bateria de testes usada para detecção de toxicidade e contaminação do ambiente aquático, principalmente por apresentar resposta altamente sensível, tempo e custo efetivo relativamente baixo.

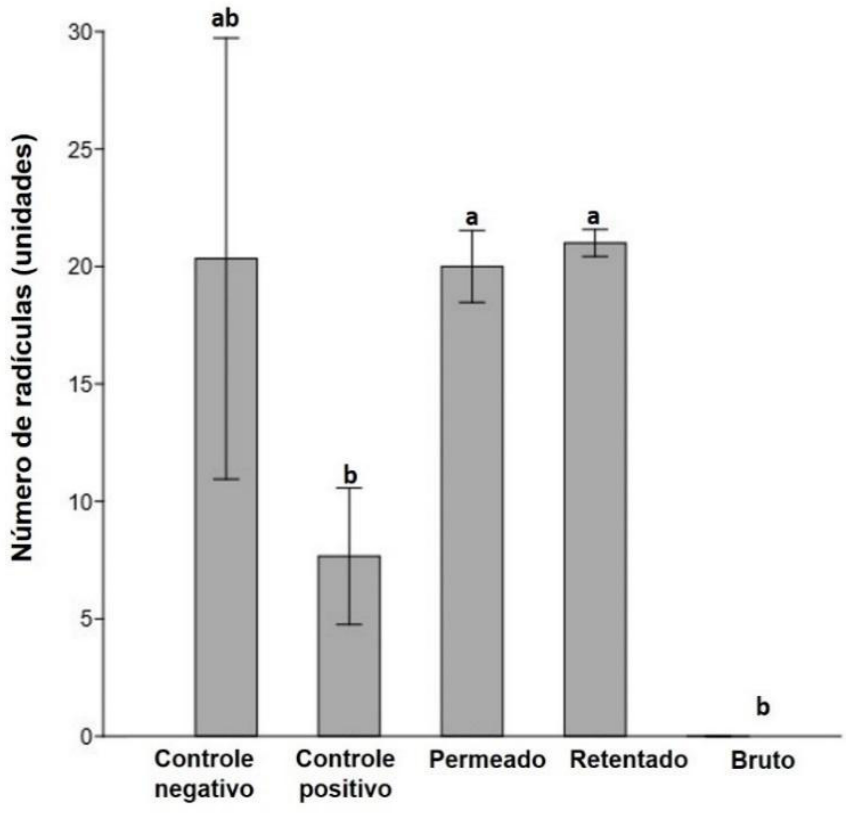

Figura 1 - Número médio de radícula entre os tratamentos.

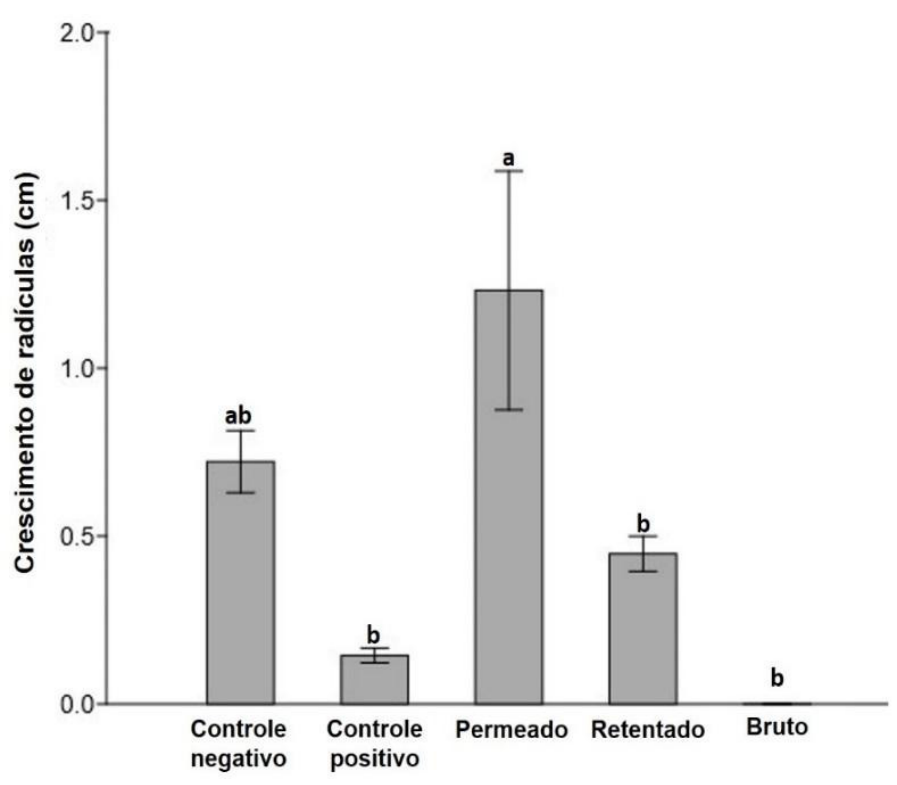

Figura 2 - Crescimento médio de radículas nos diferentes tratamentos

\section{CONCLUSÕES}

Este trabalho teve como objetivo monitorar e analisar amostras de efluente da indústria alimentícia, submetidas à técnica de osmose reversa como tratamento. Através dos resultados das análises físico-químicas e toxicológicas pode-se verificar a eficiência do processo, considerando avaliações utilizando o organismo teste Allium cepa. 
De acordo com os dados apresentados, é possível inferir a importância da utilização de ensaios de toxicidade com avaliação de modificação genética em vegetais superiores, podendo estes ser empregados para 0 monitoramento de parâmetros de qualidade de efluentes tratados.

Os resultados apresentados salientam que a liberação do efluente bruto em corpos d'água podem ser danosos para a biota associada e de uma forma indireta, para a saúde humana.

\section{AGRADECIMENTOS:}

Os autores agradecem ao CNPq $\left(\mathrm{n}^{\circ}\right.$ processo: $310253 / 2016-0$ ) e a Univates pelo apoio concedido.

\section{REFERÊNCIAS}

1. Alvim, L. B., Kummrow, F., Beijo, L. A., Lima, C. A. de A., Barbosa, S. Rev. Ambient. Água, 2011, 255.

2. Anjaneyulu, Y. , Sreedhara Chary, N., Samuel Suman Raj, D., Reviews in Environmental Science and Bio/Technology, 2005, 245.

3. Azzolini, J. C., Frinhani, E. D. M. D., Fabro, L. F. Unoesc \& Ciência-ACET, 2011, 95.

4. Barbério, A., Voltolini, J. C., Mello, M. L. S. Ecotoxicology, 2011, 927.

5. Bonumá, Nadia B. Avaliação da qualidade da água sob impacto das atividades de implantação de garimpo no município de São Martinho da Serra. Dissertação de mestrado, Santa Maria, 2006.

6. BRASIL. Resolução CONSEMA № 129, de 07 de dezembro de 2006. Dispõe sobre a definição de critérios e padrões de emissão de toxicidade de efluentes líquidos lançados em águas superficiais do estado do Rio Grande do Sul. Conselho estadual do Meio Ambiente, 2006.

7. BRASIL. Resolução CONAMA № 357 , de 17 de março de 2005. Dispõe sobre a classificação dos corpos de água e diretrizes ambientais para 0 seu enquadramento, bem como estabelece as condições e padrões de lançamento de efluentes, e dá outras providências. Conselho Nacional do Meio Ambiente, 2005.

8. BRASIL. Resolução CONAMA № 430 , de 13 de maio de 2011. Dispõe sobre as condições e padrões de lançamento de efluentes, complementa e altera Resolução №357, de 17 de março de 2005, do Conselho Nacional de Meio Ambiente- CONAMA. Conselho Nacional do Meio Ambiente, 2011.

9. COMPANHIA AMBIENTAL DO ESTADO DE SÃO PAULO (CETESB). Variáveis de qualidade de água. São Paulo, 2009. Disponível em: <http://www.cetesb.sp.gov.br/ Agua/rios/variaveis.asp\#transparencia>. Acesso em: 19 Jun. 2017.

10. Cornationi, M.B., Análises físico-químicas da água de abastecimento do município de colina - SP. Bebedouro, 2010.

11. Esteves, F. D. A. (1988). Fundamentos de limnologia. In Fundamentos de limnologia. Interciência/Finep.

12. Eremektar, G., Selcuk, H.; Meric S. Desalination, 2007, 314.

13. Farre', M., Barcelo, D. Toxicity testing of wastewater and sewage sludge by biosensors, bioassays and chemical analysis. 2003, 299.

14. Filho, E. A. F., Chui, Q. S. H. Engenharia Sanitária e Ambiental.Eng. Sanit. Ambient. vol.11 no.2 Rio de Janeiro Apr./June 2006.

15. Fiskesjö, G. Hereditas, 1985, 99.

16. Fiskesjö, G. Environmental Toxicology Risk Assesment, 1993, 331.

17. Janzen, J. G., Schultz, H. E., Lamon, A. W. Engenharia Sanitária e Ambiental, 2008, 278.

18. Kapanen A., Itävaara M. Ecotoxicity Tests for Compost Applications, Ecotoxicology and Environmental Safety 2001, 1.

19. Knasmüller, S., Gottmann, E., Steinkellner, H., Fomin, A., Pickl, C., Paschke, A., God, R., Kundi, M. Mutat Res. $1998,37$.

20. Mendes, P. N., Furtado, M. A. M., Perrone, I .T. Rev. Inst. Latic. "Cândido Tostes", 2012, 68.

21. Metcalf \& Eddy. Wastewater engineering: treatment and reuse. 4. ed. Boston: McGraw-Hill, 2004.

22. Oliveira, J. P. W., dos Santos, R. N., Pibernat, C. C., BOEIRA, J. M. 
Biochemistry and Biotechnology Reports, 2012, 15.

23. Palma-Silva, G. M. de. Diagnóstico ambiental, qualidade da água e índice de depuração do Rio Corumbataí-SP. 1999. 155 f. Diss. Dissertação (Mestrado em Manejo Integrado de Recursos)-Centro de Estudos Ambientais, Universidade Estadual Paulista, Rio Claro, 1999.

24. Prado. A. M., Godoy, H. T. Alim. Nutr., 2003, 237.

25. Prado, M. A., Godoy, H. T. Química Nova, 2007, 268.

26. Prado, R. B. Influência do uso e ocupação do solo na qualidade da água: estudo no médio rio Pardo - SP (período de 1985 a 1997). 209 p. Dissertação (Mestrado em Ciências da Engenharia Ambiental) Escola de Engenharia de São Carlos, Universidade de São Paulo, São Carlos. 1999.

27. Pérez-González A., Urtiaga, A.M., Ibáñez, R, Ortiz, I. Water Res. 2012, 267.

28. Rodrigues, S. C., Bianchini, A. Journal of the Brazilian Society of Ecotoxicology, 2007, 275.

29. Samuel, O. S.; Osuala, F. I.; Odeigah, P. G. C. African Journal of Environmental
Science and Technology, Victoria Island, 2010, 21.

30. Wetzel, R. G. Limnology. San Diego: Academic Press, 2001. 1006 p.

Tabela 2 - Resultado das análises de parâmetros físico-químicos

\begin{tabular}{c|c|c|c}
\hline \multirow{2}{*}{ Parâmetros analisados } & \multirow{2}{*}{ Efluente Bruto } & \multicolumn{2}{|c}{ Efluente Tratado } \\
\cline { 3 - 4 } & & Permeado & Retentado \\
\hline $\mathrm{pH}$ & 6,37 & 7,32 & 6,65 \\
\hline Turbidez (NTU) & 1069,0 & 13,7 & 734,0 \\
\hline Coloração (mg PtCo/L) & 46,2 & 6,0 & 426,0 \\
\hline Condutividade $\mu \mathrm{S} / \mathrm{cm}$ & 745,34 & 50,30 & 929,86 \\
\hline $\begin{array}{c}\text { Carbono Orgânico Total (COT) } \\
\mathrm{mg} / \mathrm{L}\end{array}$ & 699,7 & 6,7 & 847,5 \\
\hline Nitrogênio Total (NT) mg/L & 43,45 & 4,80 & 56,23 \\
\hline Oxigênio Dissolvido (OD) mg/L & 5,11 & 7,09 & 3,51 \\
\hline
\end{tabular}

